\title{
PRELIMINARY ANALYSIS OF THE NATIONAL CRASH SEVERITY STUDY: FACTORS IN FATAL ACCIDENTS
}

JUNE 1979

\section{U. S. DEPARTMENT OF TRANSPORTATION}

National Highway Traffic Safety Administration Washington, D.C. 20590 


\section{ABSTRACT}

This study investigates the fatalities on the National Crash Severity Study (NCSS) of towaway, passenger car accidents. The analysis is in three stages. First, NCSS fatalities are compared to the fatally-injured occupants reported on the Fatal Accident Reporting System (FARS), as a tool for evaluating the representativeness of the NCSS data. Second, estimates of the probability of fatality for NCSS are computed for various conditions, such as the incidence of fire and the sex of the occupant. Third, in cases where two factors are highly correlated, such as is the case for rollover and ejection, modeling techniques are used to help quantify the effects of each variable. The results of this study suggest the following preliminary conclusions:

1. FARS and NCSS have similar distributions of many variables. These include urbanization, size of vehicles, type damage to vehicle, occupant seating location, sex, and restraint use. Differences resulting from the investigative methods and geographical areas of the two studies are identified and assessed. 
2. On the NCSS file, many variables are associated with a much higher rate of fatality. These include (a) at the accident level: the number of vehicles involved, urbanization, and the incidence of fire or explosion; (b) at the vehicle level: the change of velocity at impact, the direction of the impacting force, and vehicle damage area; and (c) at the occupant level: seating position, age, sex, ejection, entrapment, and restraint use.

3. Rollover and ejection, which often occur together, are each independently associated with a higher rate of fatality. Of the two factors, ejection appears more related to a higher probability of fatality than does rollover alone.

NCSS is the best currently-available source of accident data for analyzing injury-related factors. This report attempts to describe the accidents occurring in the NCSS sampling areas, and suggest ideas for further research. 


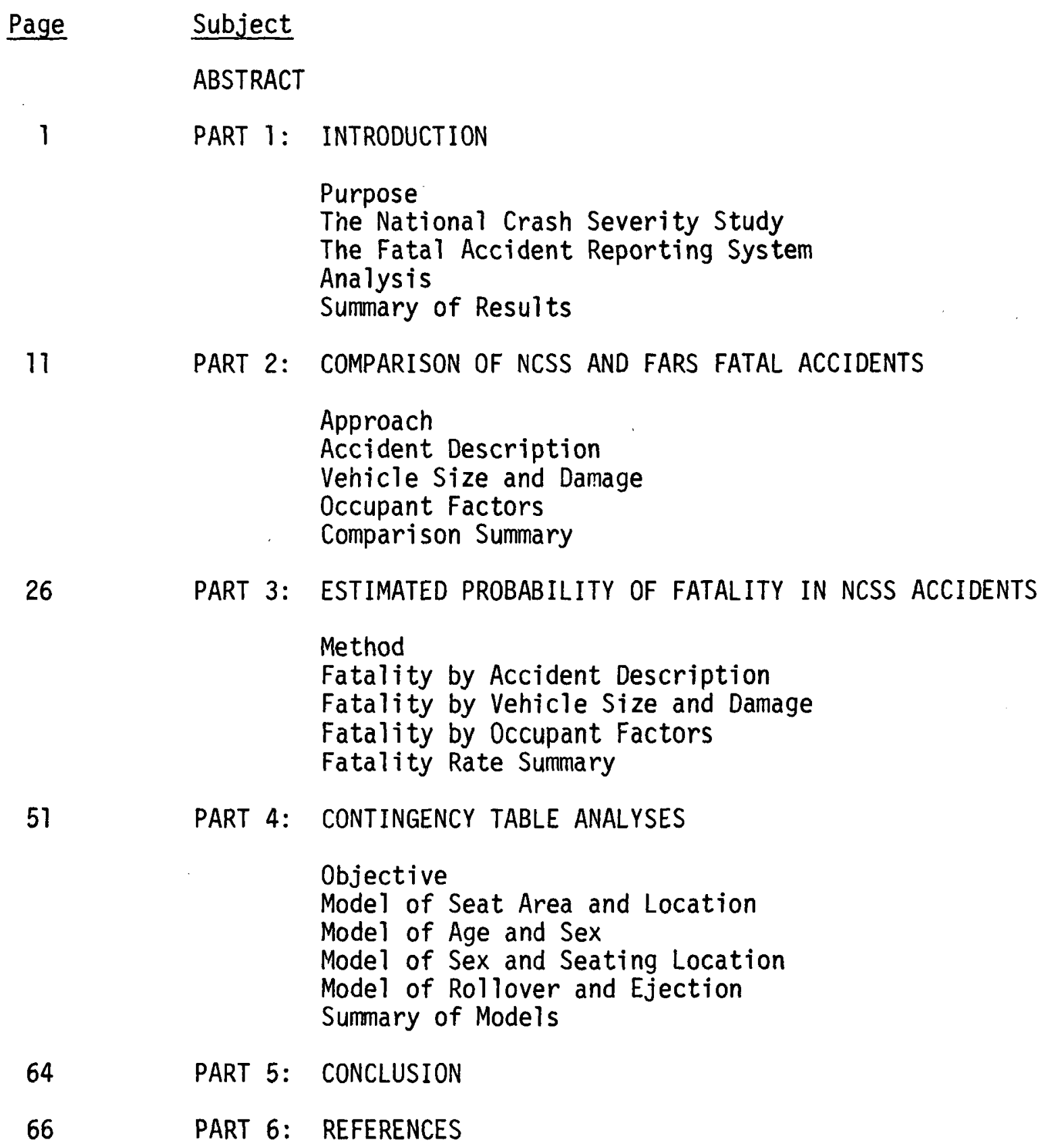

PART 2: COMPARISON OF NCSS AND FARS FATAL ACCIDENTS

PART 3: ESTIMATED PROBABILITY OF FATALITY IN NCSS ACCIDENTS

Method

Fatality by Accident Description

Fatality by Vehicle Size and Damage

Fatality by Occupant Factors

Fatality Rate Summary

PART 4: CONTINGENCY TABLE ANALYSES

Objective

Model of Seat Area and Location

Model of Age and Sex

Model of Sex and Seating Location

Model of Rollover and Ejection

Summary of Models

PART 5: CONCLUSION

66

PART 6: REFERENCES 


\section{LIST OF TABLES}

\begin{tabular}{|c|c|c|}
\hline Page & Number & Title \\
\hline & & PART 2 \\
\hline $\begin{array}{l}13 \\
16 \\
17 \\
21 \\
22 \\
23 \\
25\end{array}$ & $\begin{array}{l}1 \\
2 \\
3 \\
4 \\
5 \\
6 \\
7\end{array}$ & $\begin{array}{l}\text { Accident Description Variables } \\
\text { Vehicle Size as Determined by Wheelbase } \\
\text { Vehicle Damage Description } \\
\text { Occupant Seating Positions } \\
\text { Occupant Age and Sex } \\
\text { Occupant Restraint Use and Ejection Status } \\
\text { NCSS Age by Team }\end{array}$ \\
\hline
\end{tabular}

$\begin{array}{lr}30 & 8 \\ 31 & 9 \\ 36 & 10 \\ 37 & 11 \\ 38 & 12 \\ 39 & 13 \\ 45 & 14 \\ 46 & 15 \\ 47 & 16 \\ 48 & 17 \\ 49 & 18\end{array}$

PART 3

NCSS Estimated Probability of Fatality... ...by Various Accident Variables

....by Accident Type

...by Vehicle Size and Damage

.... and Towing for Side Impacts

...by Principal Direction of Force

...by Delta $V$

... by Seat Location

....by Age and Sex

...by Restraint Use, Ejection, and Entrapment

...by Rollover and Ejection Status

...by Overall AIS

\section{PART 4}

NCSS Data and CONTAB Fitted Model of Fatality... 


\section{PART 1: INTRODUCTION}

\section{Purpose}

This study examines the fatalities on the National Crash Severity Study (NCSS) and compares them to (1) fatalities on the Fatal Accident Reporting System (FARS); and (2) those occupants on NCSS who were not fatally injured. Many factors can influence the likelihood of occupant injury and death in an accident. In particular, the speed of the vehicles at impact and the seating location and age of the occupants are expected to affect the chance of surviving the accident.

Several other characteristics also were found to be associated with the incidence of fatality in traffic accidents. These include the number of vehicles involved in the accident, the direction of the impact force, the change in vehicular speed during impact, and such occupant characteristics as seating position, age, sex, ejection status, and restraint use.

The findings of this report are not intended to be a description of the national experience, but only of the occupants of towaway accidents in the areas sampled by NCSS. 
The National Crash Severity Study

The National Crash Severity Study (NCSS) is sponsored and conducted by the National Center for Statistics and Analysis (NCSA) of the National Highway Traffic Safety Administration (NHTSA). Seven NCSS teams investigate traffic accidents in eight sampling areas. These areas were chosen to approximate the national characteristics from areas which had available, experienced accident investigators. These sampling areas were a judgment sample - they were not chosen randomly and may not be representative of the accidents occurring nationwide. However, the sites are scattered throughout the country and include both rural and urban areas.

Within each area police-reported towaway accidents are investigated following a rigorous sampling plan. The towaway criteron includes only vehicles towed because of damage - those towed not for the convenience of the driver or because required by State law. Within this frame, all accidents with a fatality or an injury with resultant overnight hospitalization are investigated. Less severe accidents are investigated at one out of four if an occupant was transported to a medical facility, and one out of ten if no transport was involved in the accident. This sampling plan yields a higher proportion of severe accidents than normally would be found in these. areas. To adjust the figures to the correct proportions, as would occur if every accident had been investigated, each accident is multiplied by the inverse of the sampling fraction. Since only one-tenth of all accidents with no transport are investigated, each of these is multiplied by ten, reflecting a higher incidence of low-injury accidents. This process 
results in a "weighted" file which, while attempting to estimate correctly the frequency of accident factors in the overall NCSS accident population, also may be skewed by one or two unusual cases when the number of cases is smal1. This does not affect the fatal accidents on the file, which are sampled at 100 percent.

Sources of information on NCSS are "The National Crash Severity Study" (C. Kahane, R. Smith and K. Tharp) and J. Hedlund's "A Working Guide to the Nationã Crash Severity Study." (References 1 and 2). 
The Fatal Accident Reporting System

The Fatal Accident Reporting System (FARS) contains data on the census of fatal accidents occurring within the fifty States and the District of Columbia. This provides the only nationwide file of data on traffic accidents. FARS analysts use official state records to gather information on fatal traffic accidents. Traffic fatalities resulting from non-accident causes, such as suicide with a motor vehicle, are excluded from the file.

The FARS data collection forms differ from the NCSS forms. While FARS is limited to information available on State records, NCSS uses medical records, interviews, and on-site accident investigators to gather additional information. Therefore, many of the data in NCSS, such as specific injuries and measurements of vehicle damage, are not available on FARS.

In particular, FARS does not distinguish reasons for towing the vehicle, and in fact some States require the towing of all vehicles involved in a fatality.

The FARS Annual Report, produced by the NCSA, is a good source of information on this nationwide census of fatal traffic accidents. In . addition, special studies on topics of current safety interest are published from time to time (Reference 3 ). 


\section{Analyses}

As of December 1978, the NCSS file was approximately 93 percent complete for the months of January 1977 through March 1978. The file contained data on 6,216 accidents $(29,919$ when weighted), of which 372 had a fatality, and 13,525 occupants of towed passenger cars $(58,069$ weighted) of whom 442 were fatalities. The 1977 FARS file was almost 100 percent complete and contained 21,880 fatal accidents involving towaway passenger cars, and 25,818 occupant fatalities in towaway cars. The first quarter (January through March) of the 1978 FARS data was approximately 100 percent complete. Thus, each of the two accident files (NCSS and FARS) was fairly complete for the fifteen-month period January 1977 through March 1978.

The analyses of this study involved computing distributions of accident, vehicle, and occupant characteristics for NCSS fatal accidents and comparing these to (1) similar distributions for FARS fatal accidents, and (2) distributions for all NCSS accidents. The Chi-square goodness-of-fit test was used to help evaluate the differences between NCSS and FARS fatality distributions. This test was an aid in assessing if these differences could be considered real ("significantly large"), or were small enough to be attributable to chance.

The comparison of NCSS fatalities with all NCSS occupants required estimating conditional probabilities of fatality. This was estimated as the rate of fatality under various conditions, such as the percentage of people involved in rural accidents who are killed. In addition, the iterative model-fitting program CONTAB was used as a tool to separate the effects of correlated pairs of fatality factors, such as rollover and ejection. 
The results of this study pertain only to the NCSS sampling areas. To extend these results beyond NCSS it would be necessary to consider, among other things, (1) whether NCSS accidents are representative of accidents in other areas, (2) the effect of the seven percent of NCSS data that is not yet on the fifteen-month file, and which may differ from the 93 percent which has been automated, and (3) the necessity of limiting the NCSS study to towaway accidents. For these reasons, the reader should exercise caution in using NCSS distributions to estimate the incidence of accident factors in all national fatal traffic accidents. 


\section{Summary of Results}

The distributions for several important variables appear to be similar on the FARS and NCSS files. The two files have approximately the same proportions of rural vs urban accidents, large vs small cars, and front vs side damage to the vehicle in which a fatality occurred. Fatally injured occupants on the FARS and NCSS files have similar distributions for seating area, location, sex, and restraint use.

There are, however, some significant differences between the files. FARS has more single-vehicle accidents than does NCSS (48\% vs $41 \%$ ), more rollovers ( $26 \%$ vs $20 \%$ ), older fatalities $(43 \%$ vs $38 \%$ are 30 years or 01der), and fewer ejections (24\% vs $29 \%$ ). Part 2 of this report studies these variables in more detail and suggests explanations that involve the differing sampling areas and coding practices of the investigators.

When comparing these two data files, the differing definitions, codes, investigative methods, and sources of accident information must be considered. The source of FARS data is police reports and other official documents which are already prepared and available. On the other hand, NCSS uses in-depth investigations which include physical evidence and the accident scene. These investigations are specifically designed to gather certain information considered essential for accident analysis, but not generally available through record searches. 
Within the NCSS sampling areas, some factors are associated with a much higher fatality rate for the occupants involved, as discussed in detail in Part 3. The following are some of the important contrasts which were found in the analysis. The accident factors, the contrasting fatality rates for each pair of factors, and the incremental difference between the pair of factors are shown here. The actual counts of the data, from which these rates are computed, are presented in Part 2 of this report.

Factor

Accident Leve1:

Single vs multi-vehicle Rural vs urban Incidence of fire: yes vs no Fixed object vs car/vehicle

Vehicle level:

Size: small vs large Rollover vs non-rollover Damage area: side vs front Damage area: front vs side Delta V: over 12 vs up to $12 \mathrm{mph}$

Occupant level:

Location: front vs second seat

Seat area: window vs middl Age: over 30 vs up to 30 years Male vs female Restraint used: no vs yes Ejected vs not ejected Entrapped vs not entrapped
Rates of Fatality

.01315 vs .00588

.02007 vs .00397

.13514 vs .00712

.01261 vs .00633

.00878 vs .00756

.03209 vs .00756

.01153 vs .00653

.00653 vs .00074

.01725 vs .00049

.00769 vs .00580

.00766 vs .00529

.00807 vs .00750

.00909 vs .00572

.00545 vs .00313

.19856 vs .00480

.19554 vs .00469
1.3

Rate Increment

5.1

19.0

2.0

1.2

4.2

1.8

8.8

35.2

1.4

1.1

1.6

1.7

41.4

41.7 
The column "rate increment" shows, for example, that victims of rollovers have over 4 times the fatality rate of occupants of non-rollovers. The factors with the highest incremental difference are entrapment, ejection, delta $V$, and incidence of fire in the accident. Other factors, with a lower rate increment, still substantially increase the estimated probability of fatality. Most important, from the point of view of the occupant, is that unrestrained occupants suffered 1.7 times the fatality rate of restrained occupant. As contrasted with age or damage area of the vehicle, each occupant has ultimate control over the choice of this factor.

Some factors are interrelated to the degree that contingency table analysis is a useful way to sort out the effects. This is explained in Part 4. The most important result is the quantification of each of the factors "rollover" and "ejection." Since these two occurrences are correlated, special techniques are needed to estimate how much effect each factor has separately on the fatality rate. The conclusions of the analysis are that a rollover, for each ejection status, increases the fatality rate by a factor of 2.3. Similarly, an ejected person has an increased risk of almost 40 times that of an unejected person, for each of the categories rollover and non-rollover.

These estimates of the relative risk to the occupant will be used to help define the major causes of accidents, and suggest important areas for further research. When an assessment of NCSS representativeness is complete, this type of analysis will be used not only to define the 
conditions with the greatest risk to the individual occupant, but also the most frequent causes of injury and fatally. This combination of knowledge will help to determine the priorities of highway safety research 


\section{PART 2: COMPARISON OF NCSS AND FARS FATAL ACCIDENTS}

\section{Approach}

Preliminary studies of the NCSS data have shown eleven variables to be of major importance in predicting injury severity. (References 4 and 5) In evaluating the NCSS fatality file, the distributions of these elements were compared to the corresponding distributions on the FARS file. The chi-square criterion at the 5 percent level was used to help separate small differences between the files from significantly large ones. Further studies will attempt to make national estimates based upon the NCSS file, and adjustments will need to be made when the file is not consistent with the FARS data.

The distributions of the number of vehicles involved; vehicle rollover and damage description; and occupant age and ejection status were significantly different. However, the rural/urban classification of the scene, size of the vehicle, occupant seat area and location, and occupant sex and restraint use each had distributions which were consistent with those on the FARS file. These differences were small enough to be the result of chance.

The following sections compare the iwo files in more detail for each of these accident factors. 


\section{Accident Description}

Table 1 shows the higher proportion of FARS accidents which involve only a single vehicle: 48 percent, as contrasted with only 41 percent of the NCSS fatal accidents. This is a significant difference, using the chi-square criteria at the 5 percent level. The probability (P) of a larger difference for normally-distributed, independent variables is only 0.008 . Thus, the proportion of single-vehicle accidents appears to be very dependent upon which file is used as the source of the information.

One possible explanation for this difference could involve differences in the urbanization of the sampling areas of the two studies, because rural accidents are more frequently single-vehicle accidents than are urban accidents. The FARS file has a slightly higher proportion of rural accidents $(61.9 \%)$ than does the NCSS accident file (59.9). This difference was not found significant using the chi-square decision rule $(P=0.435)$ and is not large enough to account for the higher frequency of singlevehicle accidents. In fact, FARS rural accidents involve a single vehicle $50 \%$ of the time, as contrasted with a rate of only $45 \%$ for NCSS. Similarly for urban accidents, $45 \%$ on FARS are single-vehicle, as opposed to a rate of only $36 \%$ for NCSS. Urbanization does not appear to be the major cause of the difference between the two files in the number of vehicles involved. The FARS rate of single-vehicle involvement is higher than that of NCSS, regardless of urbanization. 
TABLE 1: Accident Description Variables - Counts and Percentages of Known Data for Fatalities Only.

NCSS Data

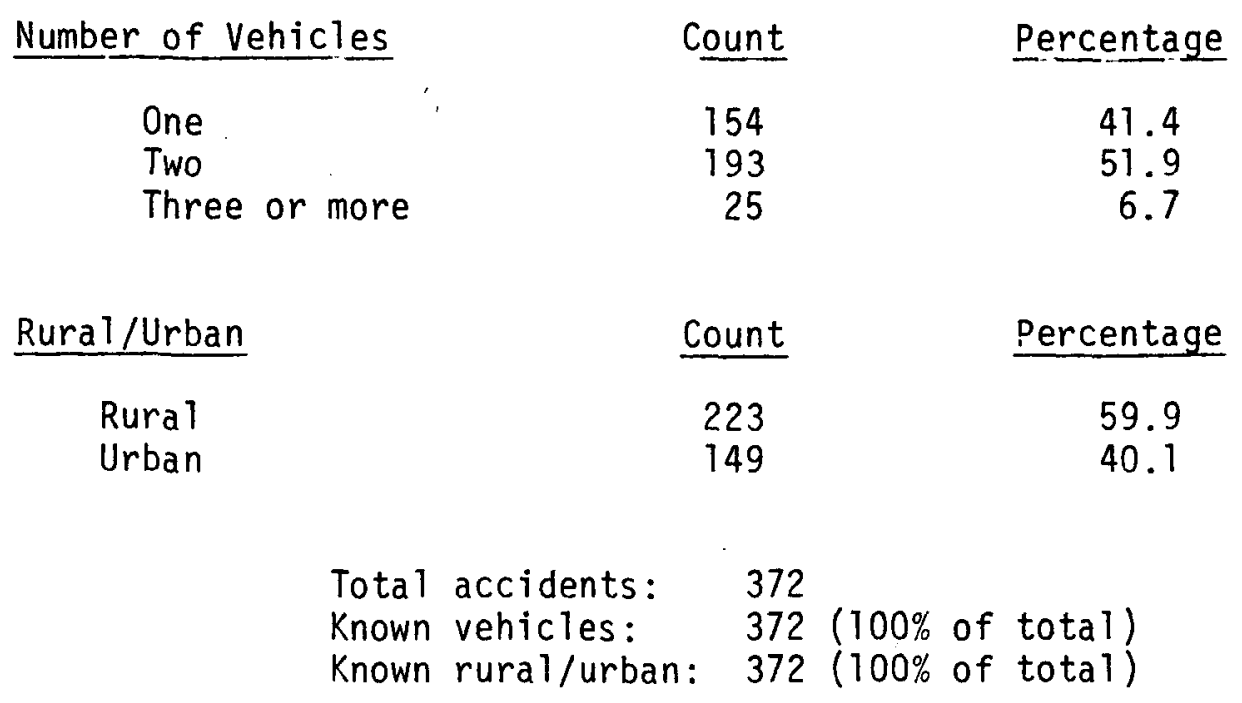

FARS Data

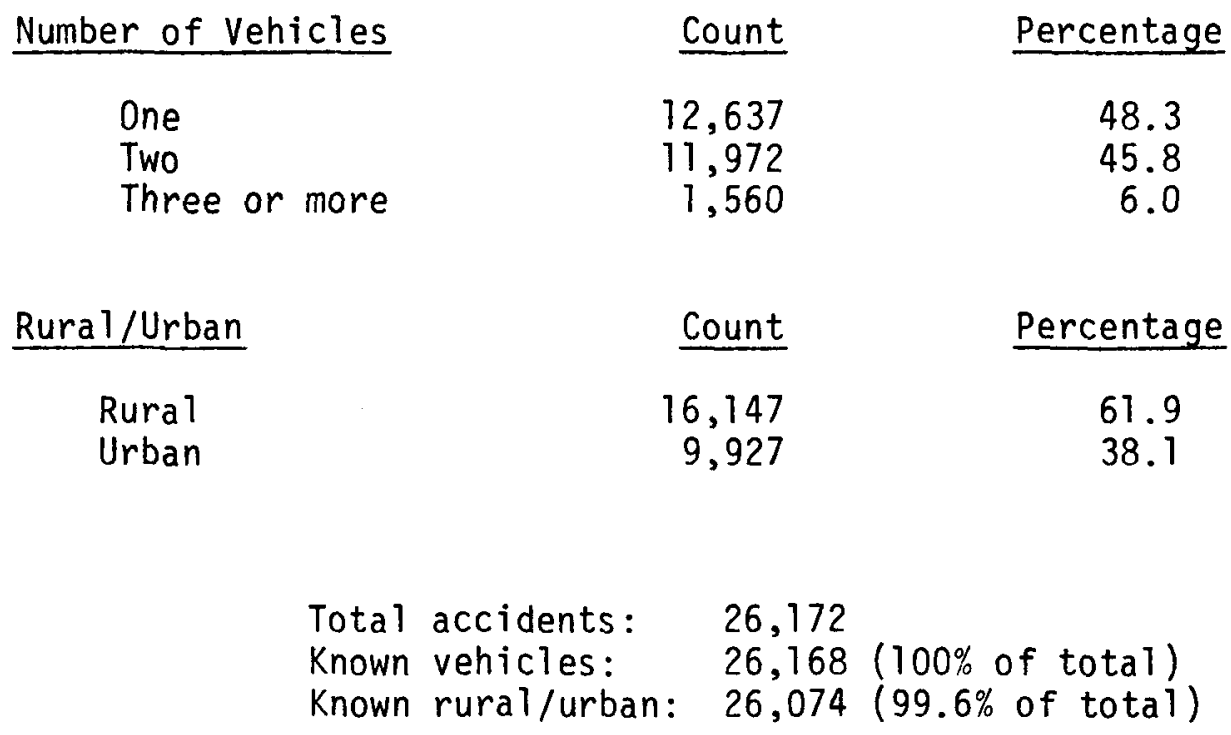


Vehicle Size and Damage

The size of the vehicle in which at least one fatality occurred is shown for NCSS and FARS in Table 2. The wheelbase is used to define the six size categories of minicar (up to 94 inches long) through large (over 123 inches long). Wheelbases for vehicles in 1978 FARS cases are not currently available, so 1977 figures are used. Almost 50 percent of the wheelbases on NCSS, and 39\% on FARS for 1977 cannot be uniquely determined from the vehicle identification number (VIN), and are therefore unknown.

The FARS file has a higher proportion of small cars through the compact category than does NCSS $(34.6 \%)$. However, the large proportion of unknown makes it hard to determine if this difference is large enough to be considered real. The chi-square test does not assess the difference to be significantly large $(P=0.136)$

While the NCSS file is based upon vehicles towed from the scene because of damage, the closest thing in FARS is the variable "towaway," which includes vehicles towed for reasons other than disabling damage. However, the NCSS file contains only one case of a person who was killed in a non-towaway vehicle. This indicates that most fatal accidents involve a great deal of damage to the vehicle as well.

Using the rollover variable present on the 1978 FARS forms, $25.8 \%$ of vehicles which contained a fatality also rolled over in the course of the accident, as shown in Table 3. For NCSS, this variable 
is not available, and rollovers are determined by a type of damage distribution of "rollover" for either of the two most severe impacts. The different ways of describing a rollover may in part account for the significantly lower rate of fatal rollovers on NCSS $(P=0.008)$ only $19.6 \%$ of the vehicles involved a fatality. This lower rate is also consistent with the lower proportion of single vehicle accidents on NCSS, because 90 percent of rollovers do not involve another vehicle. For planar, non-rollover accidents, the FARS variable, "principal impact point," is not directly comparable to the "area of damage" recorded on the NCSS file. While FARS uses twelve clock positions to locate the damage, NCSS uses the less precise designation of front/back/left/ right to record which side was damaged. The FARS variable was converted into the NCSS damage variable and the results of these calculations are shown in Table 3. For these non-rollover accidents, the ratio of front damage: side damage is similar for the two files. For NCSS, the ratio is 160: $119=1.3$; the FARS ratio is $6,026: 4,943=1.2$. The largest differences between the damage distributions appear to be the result of the different coding practices for the rollover situation. 
TABLE 2: Vehicle Size as Determined by Wheelbase - Counts and Percentages of Known Data for Fatalities Only.

NCSS Data

Size, Wheelbase

Minicar

(up to 94")

Subcompact

(95-102")

Compact

(103-110")

Intermediate

$\left(111-117^{\prime \prime}\right)$

Full Size

(118-123")

Large

(Over 123")

$\begin{array}{lcc}\text { Count } & \text { Percentage } & \begin{array}{c}\text { Cumulative } \\ \text { Percentage }\end{array} \\ 6 & 3.1 & 3.1 \\ 30 & 15.7 & 18.8 \\ 30 & 15.7 & 34.6 \\ 68 & 35.6 & 70.2 \\ 41 & 21.5 & 91.6 \\ 16 & 8.4 & 100.0\end{array}$

Total vehicles: 381

Known size: 191 ( $50 \%$ of total)
FARS Data

Size, Wheelbase

Minicar

(up to 94")

Subcompact

(95-102")

Compact

(103-110")

Intermediate

(111-117")

Full Size

(118-123")

Large

(over 123")
Count

1,006

2,217

2,254

4,224

2,852

1,183
Cumulative

Percentage

7.3

7.3

16.1

23.5

16.4

39.9

70.6

30.8

20.8

91.4

100.0

Total vehicles: 22,425

Known size:13,736

$(61.3 \%$ of total) 
TABLE 3: Vehicle Damage Description - Counts and Percentages of Known Data for Fatalities Only

\section{NCSS Data}

Vehicle Damage

Rollover

Non-rollover

Back

Front

Left

Right

other known

\begin{tabular}{rr} 
Count & Percentage \\
\cline { 2 - 2 } 69 & 19.6 \\
283 & 80.4 \\
2 & 0.6 \\
160 & 45.5 \\
55 & 15.6 \\
64 & 18.2 \\
2 & 0.6
\end{tabular}

Total vehicles: 381

Known Damage $\quad 352(92.4 \%$ of total)

\section{FARS Data}

\begin{tabular}{lcc} 
Vehicle Damage & Count & Percentage \\
\hline Rollover & 4,005 & 25.8 \\
Non-rollover & 11,531 & 74.2 \\
Back & 296 & 1.9 \\
Front & 6,026 & 38.8 \\
Left & 2,633 & 16.9 \\
Right & 2,310 & 14.9 \\
Other known & 266 & 1.7 \\
& $\begin{array}{l}\text { Total vehicles: } \\
\text { Known damage: }\end{array}$ & $15,743,536(98.7 \%$ of total)
\end{tabular}


Occupant Factors

The seating positions of fatalities are shown in Table 4. Approximately two-thirds of these people were in the driver's seat at the time of the accident: 68.1 percent of NCSS fatalities were left front seat passengers (drivers), as were about the same number, 62.2 percent, in FARS $(P=0.752)$.

The rows and columns do not always add to the totals shown because of the small number of people with a seat area which is other than those shown (e.g., "lying across seat") or unknown.

The distributions are not significantly different: approximately 92 percent of fatalities are in the front seat $(P=0.454)$ and $70-71$ percent (for FARS and NCSS, respectively) are in a left side seat $(P=0.823)$.

The joint distribution of age and sex is shown in Table 5 . The proportion by sex is not significantly different between the two files $(P=0.374)$; approximately one-third of the fatalities are famale. However, the NCSS fatalities are significantly younger than their FARS counterparts $(P=0.021)$. While 62 percent of the people killed within the NCSS study area are under 30, this group accounts for only 57 percent of the State census of fatalities. A look at the under 30 group by sex shows that both males and females are slightly younger in the NCSS study. The NCSS data shows that restraint use, as determined by the accident investigator, is about 5.4 percent for fatalities. Table 6 
contrasts this with the FARS usage of 4.1 percent. (If only the States which report usage are considered, FARS also shows that $5 \%$ of the fatalities were restrained.) A very small proportion of those killed in passenger cars were using any form of restraint, and the difference between the two files is not significant at the chi-square 5 percent level $(P=0.230)$.

Using the chi-square test leads to the conclusion that there is a difference in terms of ejection $(P=0.042)$. While 24.2 percent of the fatalities on FARS were partially or totally ejected, 28.7 percent of the NCSS fatalities whose ejection status was known were ejected to some degree. The rate for both total and partial ejection is higher in the NCSS sampling areas for the known data.

However, there is a much higher rate of unknown for NCSS ejection status: for 13.3 percent of the fatalities, it is not known whether or not the victim was ejected. This would be sufficient to account for the difference: if all of these people were actually not ejected, the two distributions, for NCSS and FARS, would be similar. Computing ejection rates as percentages of total occupants (instead of using only occupants with known ejection status as the base) results in estimates which are similar for the FARS and NCSS fatalities. The rates for FARS and NCSS, respectively, are:

1) total ejection: $20.2 \%$ vs $21.8 \%$

2) partial ejection: $3.5 \%$ vs $3.8 \%$

3) no ejection: $74.3 \%$ vs $61.8 \%$

4) unknown ejection status: $1.9 \%$ vs. $13.3 \%$ 


\begin{abstract}
A possible explanation of the difference in the rates of ejection involves the different methods for determining that no ejection took place. A tendency on the part of the NCSS analysts to require more proof that no ejection took place would account for the different rates on the two files.
\end{abstract}


TABLE 4: Occupant Seating Positions - Counts and Percentages of Known Data for Fatalities Only.

NCSS Data

Seat Area

$\begin{array}{lcccc}\text { Location } & \text { Left } & \text { Middle } & \text { Right } & \text { //Total } \\ \text { Front } & 292 & 10 & 97 & 394 \\ \text { Second } & (68.7 \%) & (2.3 \%) & (21.2 \%) & (91.4 \%) \\ \text { Third } & 11 & 6 & 18 & 36 \\ & (2.6 \%) & (1.4 \%) & (4.2 \%) & (8.4 \%) \\ \text { Total } & - & 1 & - & 1 \\ & - & (0.2 \%) & - & (0.2 \%) \\ & 303 & 17 & 109 & \\ & (70.6 \%) & (4.0 \%) & (25.4 \%) & \\ & & \text { Total occupants: } 442 & \\ & & \text { Known seating: } 429(97.1 \% \text { of total) }\end{array}$

FARS Data

$\begin{array}{lcccc}\text { Location } & \text { Left } & \text { Middle } & \text { Right } & \text { //Total } \\ \text { Front } & 19,825 & 647 & 6,789 & 27,276 \\ & (67.2 \%) & (2.2 \%) & (23.0 \%) & (92.4 \%) \\ \text { Second } & 858 & 402 & 971 & 2,236 \\ & (2.9 \%) & (1.4 \%) & (3.3 \%) & (7.6 \%) \\ \text { Third } & 5 & 5 & 2 & 13 \\ & (0.0 \%) & 0.0 \%) & (0.0 \%) & (0.0 \%) \\ & & & & \\ \text { Total } & & & & \end{array}$

Total occupants: $\quad 30,855$

Known seating: 29,504 (95.6\% of total) 
TABLE 5: Occupant Age and Sex - Counts and Percentages of Known Data for Fatalities Only.

NCSS Data

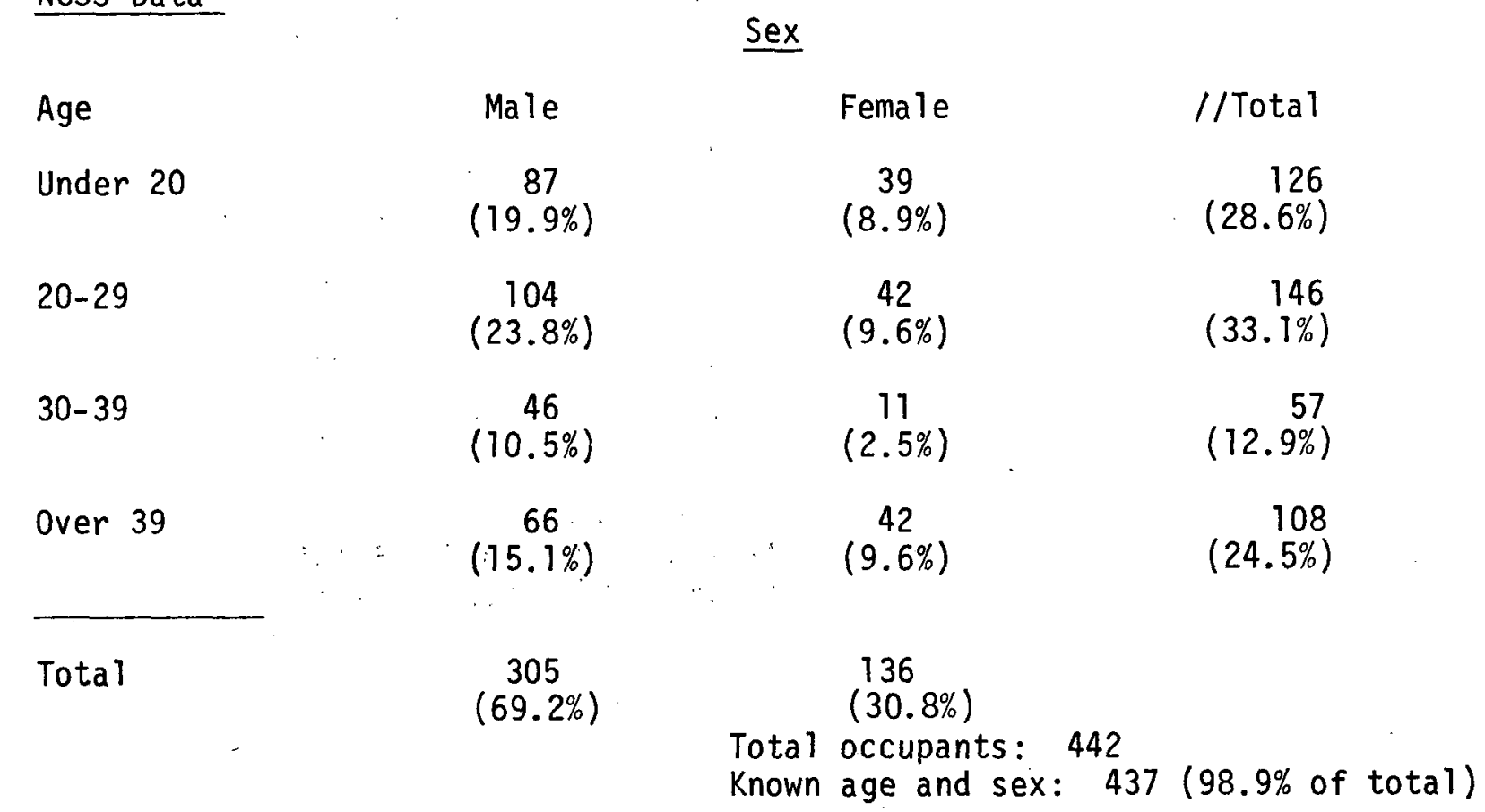

FARS Data

\section{Sex}

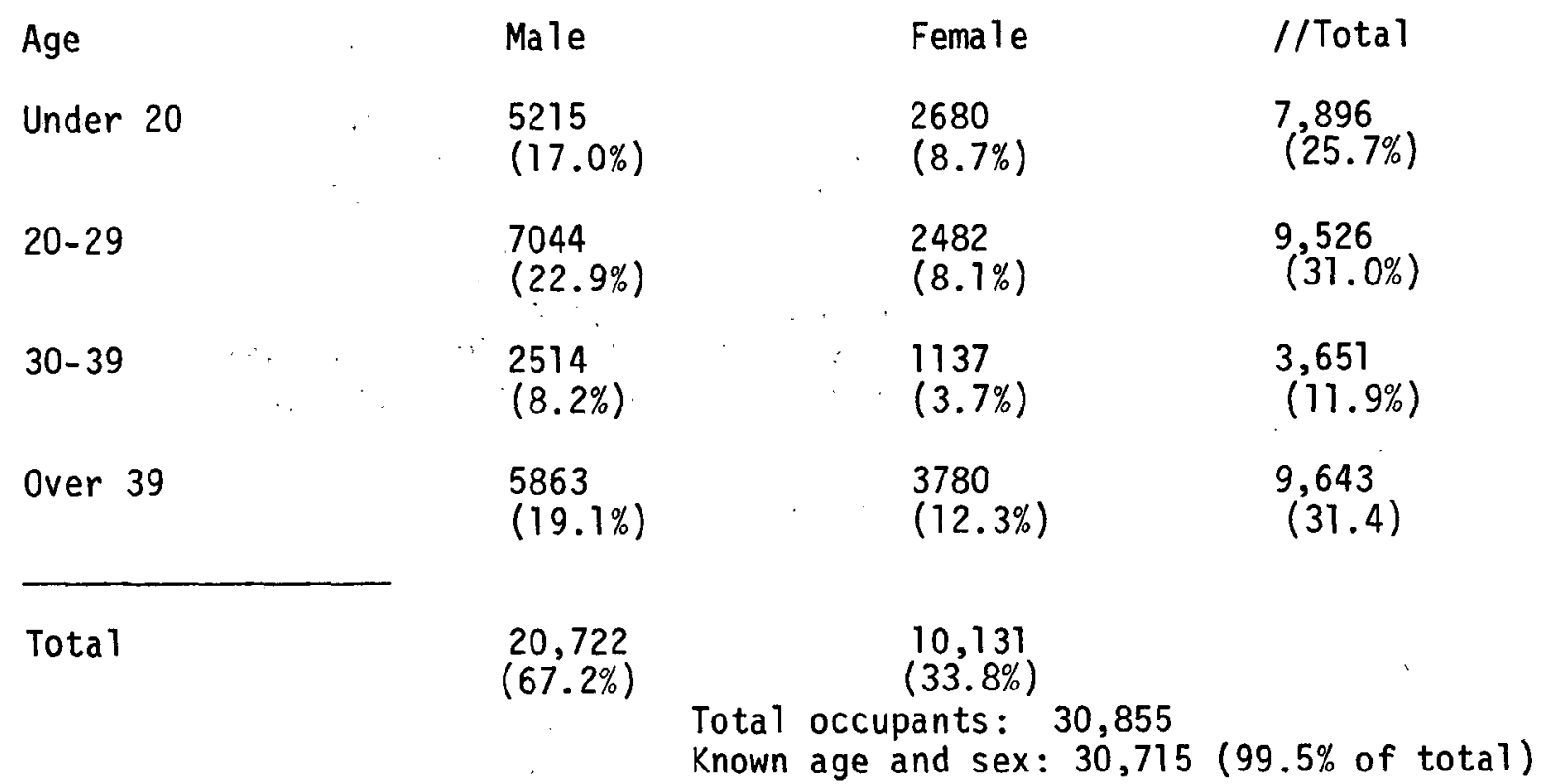


TABLE 6: 0ccupant Restraint Use and Ejection Status

- Counts and Percentages of Known Data for Fatalities only.

NCSS Data

Restraint Used

Count

Yes

No

Ejection Status

None

Total

Partial
21

371

Count

273

93

17
Percentage

5.4

94.6

Percentage

71.3

24.3

4.4

Total occupants: 442

Known restraint: $392(88.7 \%$ of total)

known ejection: 383 ( $86.7 \%$ of total)

\section{FARS Data}

Restraint Used

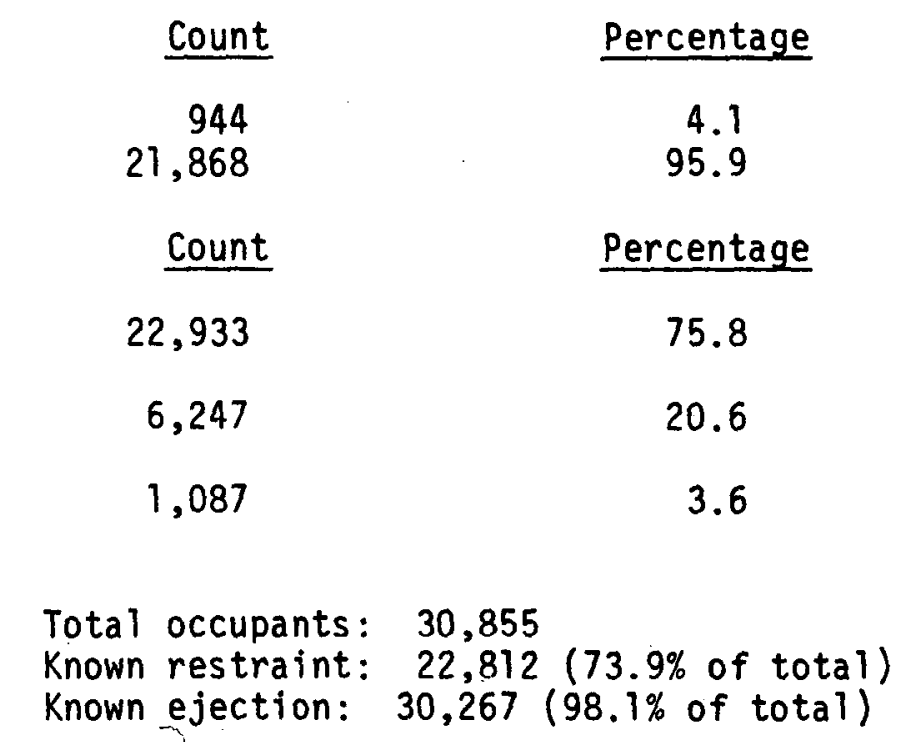

Yes

No

Ejection Status

None

Total

Partial 


\section{Comparison Summary}

The NCSS fatal file has distributions which are similar to FARS for many important variables. The description of the accident scene as rural or urban, the vehicle size, and such occupant factors as seat area, location, sex, and restraint use are consistent. Thus, over all, the NCSS file appears to be a good basis for estimates of accident factors. Differences between the two files for estimates of proportions of rollovers and ejections appear to be the result of the coding practices and investigative methods. In analyzing these variables, it is necessary to understand under what definitions and conventions the data were collected.

NCSS areas have a slightly higher proportion of younger fatalities. Table 7 shows that the age distributions for fatalities differ between teams because of the areas they serve (many of which are college areas). Also, NCSS has a lower proportion of single-vehicle accidents. These differences, while statistically significant, are small (on the order of $10 \%$ ) and should not drastically affect the results of the analysis. Despite these differences, NCSS is the best available source of accident data which includes in-depth investigations of physical evidence and official reports. 
TABLE 7: NCSS Age by Team - Counts and Percentages of Known Data for Fatalities Only.

$\underline{\text { Team }}$

Calspan (New York)
HSRI (Michigan)*
Indiana *
Kentucky *
Miami
Southwest (Texas)
Dynsc (California)

Aggregate

FARS

*Inuicates a college area
Age

\begin{tabular}{lr} 
Under 30 & 30 and Over \\
\hline $35(61 \%)$ & $22(39 \%)$ \\
$35(67 \%)$ & $17(33 \%)$ \\
$61(62 \%)$ & $37(38 \%)$ \\
$35(70 \%)$ & $15(30 \%)$ \\
$9(43 \%)$ & $12(57 \%)$ \\
$87(61 \%)$ & $55(39 \%)$ \\
$10(59 \%)$ & $7(41 \%)$ \\
$272(62 \%)$ & $165(38 \%)$ \\
$422(57 \%)$ & $13,294(43 \%)$
\end{tabular}


PART 3: ESTIMATED PROBABILITY OF FATALITY IN NCSS ACCIDENTS

Method

The probability of fatality was estimated for the NCSS sampling areas by computing the proportion of fatalities for each of several characteristics. Thus, the probability of fatality in NCSS rural accidents is estimated by the weighted data by:

$$
\begin{aligned}
& \frac{\text { fatalities in rural accidents }}{\text { al1 occupants in rural accidents }} \\
& =\frac{264}{13,157}=.02007 .
\end{aligned}
$$

It must be emphasized that these estimates are for towaway passenger car accidents in the NCSS sampling areas only, and no estimates of national fatality rates are made at this time.

The number of fatalities is the actual count of occupants killed in the NCSS areas. However, other accidents are sampled at 100 percent, 25 percent, or 10 percent depending upon the severity of the resulting injuries. The less severe, but more frequent, accidents are then weighted by the inverse of the sample fraction $(1,4$, or 10) to estimate the actual occurrence in the NCSS areas. This has the effect of increasing the size of the file, and thus of the apparent statistical significance of the findings. In estimating the fit of the CONTAB models, no adjustments have been made for this effect. 


\section{Fatality by Accident Type}

The fatality rate for occupants, given various accident level descriptors, is shown in Table 8. The number of vehicles involved in the accident distinguishes car/car from car/object impacts. For singlevehicle accidents, which are vehicles hitting an object or the ground, the estimated probability of fatality is over twice as high as for multi-vehicle impacts. Single vehicle accidents account for 41 percent of the fatalities, but only 24 percent of the total occupants in NCSS crashes. Thus, for towed NCSS area vehicles, striking something other than a vehicle has a higher fatality rate than does striking another car.

The estimated probability of fatality, given a rural or an urban land use, is also shown in Table 8. Rural accidents have over 5 times as high a risk as do urban accidents. While under 23 percent of the occupants were involved in rural accidents, these people represented almost 60 percent of the fatalities. Apparently, urhan impacts are relatively lower-velocity, less severe crashes than are those in the less restricted rural environment. This does not imply that cities are safer places to drive. No exposure data is available which could measure the amount of driving done, in miles or in hours. These probabilities of fatalities are conditional on an accident occurring and no estimates of the probability of the impact can be made at this time. 
Also estimated in the same table is the frequency of fire involvement in the accident. This variable does not record which vehicle suffered fire damage, but only that at least one of the vehicles did. The fatality rate in the presence of fire was 19 times the fatality rate in non-fire accidents. In part, this probably is an indication of the severity of the crash - more severe impacts produce both fires and fatalities. It cannot be assumed that the fire caused the fatality.

Table 9 relates the probability of fatality to a description of the accident. Accident type is a finer breakdown of the number of vehicles involved which is shown in Table 8 . One-vehicle accidents include car/fixed object categories and principal rollovers. Two-vehicle accidents include car/vehicle categories and sideswipes. Three or more vehicles in an accident are generally a chain collision. Because a single description of the whole accident is required, this variable is not as precise as the vehicle-level variables in describing the damage to each vehicle, but it does give an approximation of the accident sequence.

Car/fixed object accidents have twice the fatality rate that occupants of car/vehicle collisions suffer. Comparisons within the car/vehicle categories reveals that the risk in a head-on crash is two and a half times that in a side impact. (Fatality rates for a side impact accident include the occupants of both the car struck in the side and the striking vehicle.) Angle impacts have lower rates t'ian the corresponding direct hits in both the case of frontal 
and side collisions. In the case of impact with a fixed object, a towed side impacted vehicle has three times the fatality rate of a towed frontally damaged car.

The highest fatality rates are for accidents described as side into a fixed object, rollover, and head-on. The lowest rates are for sideswipes, chain collisions, and rear impacts. 
TABLE 8: NCSS Estimated Probability of Fatality by Various Accident Variables

Number of

Vehicles

One

Two

Three or more

Rural/Urban

Rura 1

Urban

Fire

Yes

No

\section{Fatalities}

182

232

28

264

178

30

412
Estimated Probability

Occupants of Fatality

$13,840 \quad .01315$

$37,152 \quad .00624$

$7,077 \quad .00396$

$13,157 \quad .02007$

$44,865 \quad .00397$

$222 \quad .13514$

$57,847 \quad .00712$ 
TABLE 9: NCSS Estimated Probability of Fatality by Accident Type

\begin{tabular}{|c|c|c|c|}
\hline $\begin{array}{l}\text { Type of } \\
\text { Impact }\end{array}$ & Fatalities & $\begin{array}{l}\text { A11 } \\
\text { Occupants } \\
\end{array}$ & $\begin{array}{l}\text { Estimated } \\
\text { Probability } \\
\text { of Fatality } \\
\end{array}$ \\
\hline Car/vehicle: & 220 & 34,729 & .00633 \\
\hline Head on & 83 & 5,135 & .01616 \\
\hline Angle front & 4 & 910 & .00440 \\
\hline Side & 106 & 16,809 & .00631 \\
\hline Angle side & 13 & 3,789 & .00343 \\
\hline Rear & 14 & 8,086 & .00173 \\
\hline Car/fixed object: & 127 & 10,073 & .01261 \\
\hline Front & 70 & 7,942 & .00881 \\
\hline Side & 56 & 2,033 & .02755 \\
\hline Rear & 1 & 98 & .01020 \\
\hline Other: & 87 & 11,789 & .00738 \\
\hline Principal rollover & 58 & 2,150 & .02698 \\
\hline Sideswipe & - & 1,120 & - \\
\hline Undercarriage & 2 & 721 & .00277 \\
\hline Chain collision & 1 & 2,674 & .00037 \\
\hline Other/unknown & 26 & 5,124 & .00507 \\
\hline
\end{tabular}

(Note: since this variable describes the entire accident, car/vehicle accident types include counts of all occupants in all involved vehicles despite individual damage areas.) 


\section{Fatality by Vehicle Size and Damage}

Table 10 shows fatality rates by various sizes of vehicles, as defined previously by the length of the wheelbase. While "minicar," the smallest size, has the highest fatality rate, and "large," the largest size, has the lowest fatality rate, it is not clear if there is a steady trend of increasing rate with decreasing size. The average of of the three smallest categories is .00878 as contrasted with .00756 for the three largest categories, indicating that size may be an advantage for occupants of towed vehicles.

Estimates of occupant fatality rates for various vehicle damage descriptions are also shown in Table 10. Rollovers appear to have the highest risk of fatality for NCSS towaway accidents: four times the fatality rate of non-rollovers in general. Note that while only 5 percent of all occupants were in a vehicle which rolled over, these people are 18 percent of all fatalities. A comparison of the specific impact areas for non-rollovers shows a higher fatality rate for vehicles hit in the side than for frontally damaged vehicles.

A closer examination of the typical side impact is useful because of the wide range of accidents which may result in a particular damage area. Shown in Table 11 is fatality information for two-vehicle accidents in which one passenger car received frontal damage as the result of striking another car in the side. As a control, only accidents in which both vehicles required towing are considered. Note that in this case the occupants of the struck vehicle have over eight times the fatality rate of the occupants of the striking vehicle. 
The NCSS file is, for practical reasons of accident identification and standardization, limited to accidents in which at least one vehicle was damaged sufficiently to require towing. Therefore, it is important to consider the question of whether the striking or the struck vehicle is more often towed. A towed vehicle is more often the case vehicle for which occupant fatality information is available. A large difference in the rate of towing would mean that occupant information for the lessoften towed vehicle would be biased towards the more severe accidents which resulted in towing.

Table 11 shows that the rate of towing in side impact accidents is almost the same for the striking and struck vehicle. The struck car is towed 74 percent of the time, the striking car is towed 75 percent of the time, and in 49 percent of the cases both vehicles are towed. It appears that the towing criterion does not bias the file towards either side or front damaged vehicles, and the relative fatality rates should be consistent with the total accident picture of the NCSS sampling areas for this particular type of crash.

The direction of force (DOF) for horizontal impacts is measured from 1 to 12 and corresponds to the hours on a clock. A DOF of 12 is perpendicular to the front of the vehicle. Table 12 gives fatality rates for the various force directions, including zero for non-horizontal forces such as an undercarriage. The DOF is not a substitute for the area of damage, but the two variables together give information on the impact. A DOF of 1 to the front is slightly less than a direct impact, 
while a DOF of 1 to the right side might be a sideswipe. Forces from the clock positions 2-4 and 8-10 are often side damage, while 11-12-1 and 5-7 are frequently front and rear damage, respectively. Thus, the fatality rate for each DOF is similar to that for the particular damage area which is often associated with it.

In addition, fatality rates for the DOF categories which correspond to direct impacts into one of the four surfaces are higher than for indirect or glancing impacts. O'clock positions 3,6,9, and 12 have higher rates than do the adjoining clock positions representing less direct impacts.

Delta $V$ is the change in velocity during impact, and measures the severity of the crash. A high delta $V$ indicates that a large amount of energy was absorbed during impact by the crushing of the vehicles. The CRASH program is an algorithm which is used to estimate the change in velocity, and the values in Table 13 are based upon measurements of the vehicle damage.

Consistently, higher delta $V$ categories have associated with them higher fatality rates. Ranging from only one fatality for 5,939 occupants in the under $7 \mathrm{mph}$ category through one quarter of the group involved in impacts with delta $V$ over $48 \mathrm{mph}$, there is an increase in the estimated probability of fatality accompanying the increased crash severity.

The CRASH program was not run for almost half of the occupants. The algorithm is not applicable in accidents involving non-horizontal forces, such as rollovers and undercarriage; or when impacting a 
yielding fixed object, such as is the case when striking and breaking a small tree. In other cases, there is not enough damage information available, as when a vehicle is driven out of the area, or otherwise cannot be located or examined.

If the missing values tended to be for the more severe crashes, this could bias estimates based upon the known factor. The percentages of known delta $V$ for fatalities is almost the same as for the file as whole: 53 percent vs. 51 percent. The fatality rate for occupants with known delta $V$ is slightly lower than that for occupants with unknown delta $V$ : 0.00729 vs. 0.00798 . This difference is small enough to not be considered significant at the .05 chi-square level. Using this criterion, the occupant fatality rate for known delta $V$ is consistent with that for the file as a whole. Thus, the large number of cases with unknown delta $V$ does not seem to bias the results significantly in favor of, or against, the less severe crashes.

The delta $V$ is estimated to be correct to within 20 percent, for those crashes for which it was designed. Thus, at the higher values of delta $V$, the error becomes a larger factor in miles per hour. A delta $V$ of $20 \mathrm{mph}$ is estimated to be in error by about $\pm 4 \mathrm{mph}$. However, a computed delta $V$ of $40 \mathrm{mph}$, can easily be in error by $\pm 8 \mathrm{mph}$. This error is introduced by the many simplifying assumptions about the accident sequence crash dynamics, and vehicle stiffness characteristics which are necessary in an algorithm such as delta $V$. The reader should consider these estimates with caution, and not attempt to equate them to barrier equivalent velocities. 
TABLE 10: NCSS Estimated Probability of Fatality by Vehicle Size and Damage.

\begin{tabular}{|c|c|c|c|}
\hline Size & Fatalities & $\begin{array}{l}\text { A11 } \\
\text { Occupants }\end{array}$ & $\begin{array}{l}\text { Estimated } \\
\text { Probability } \\
\text { of Fatality }\end{array}$ \\
\hline Minicar & 6 & 536 & .01119 \\
\hline Subcompact & 34 & 4,457 & .00763 \\
\hline Compact & 37 & 3,774 & .00980 \\
\hline Intermediate & 82 & 10,527 & .00779 \\
\hline Full Size & 47 & 6,157 & .00763 \\
\hline Large & 19 & 2,899 & .00655 \\
\hline $\begin{array}{l}\text { Vehicle } \\
\text { Damage } \\
\end{array}$ & Fatalities & $\begin{array}{l}\text { A11 } \\
\text { Occupants } \\
\end{array}$ & $\begin{array}{l}\text { Estimated } \\
\text { Probability } \\
\text { of Fatality }\end{array}$ \\
\hline Rollover & 75 & 2,337 & .03209 \\
\hline Non-rollover: & 336 & 44,458 & .00756 \\
\hline Back & 2 & 2,707 & .00074 \\
\hline Front & 184 & 28,163 & .00653 \\
\hline Left & 73 & 6,539 & .01116 \\
\hline Right & 75 & 6,302 & .01190 \\
\hline other known & 2 & 747 & .00268 \\
\hline
\end{tabular}


TABLE 11: NCSS Estimated Probability of Fatality and Towing for Side Impacts.

Two-vehicle accidents, one car striking another in the side, and both vehicles sufficiently damaged to require towing:

Vehicle

Damage

Front (striking)

side (struck)

Left side

Right side

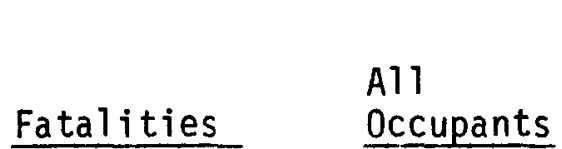

4,617

4,428

2,124

2,304
Estimated Probability of Fatality

.00108

.00903

.00659

.01128

Two-vehicle accidents, one car striking another in the side: rate of towing required:

\begin{tabular}{lccc} 
& & \multicolumn{2}{c}{ Front } \\
Side & Towed & Not Towed & Tota1 \\
Towed & 2,947 & 1,486 & 4,433 \\
& $(49.4 \%)$ & $(24.9 \%)$ & $(74.3 \%)$ \\
Not Towed & 1,537 & - & 1,537 \\
& $(25.7 \%)$ & - & $(25.7 \%)$ \\
\hline \multirow{2}{*}{ Tota 1} & 4,484 & 1,486 & 5,970 \\
& $(75.1 \%)$ & $(24.9 \%)$ & $(100 \%)$
\end{tabular}


TABLE 12: NCSS Estimated Probability of Fatality by Principal Direction of Force.

\begin{tabular}{|c|c|c|c|}
\hline DOF & Fatalities & $\begin{array}{c}\text { A11 } \\
\text { Occupants } \\
\end{array}$ & $\begin{array}{l}\text { Estimated } \\
\text { Probability } \\
\text { of Fatality }\end{array}$ \\
\hline 0 (Non-horizontal) & 63 & 2,739 & .02300 \\
\hline 1 & 42 & 5,561 & .00755 \\
\hline 2 & 35 & 4,531 & .00772 \\
\hline 3 & 15 & 694 & .02161 \\
\hline 4 & 10 & 574 & .01742 \\
\hline 5 & 2 & 496 & .00403 \\
\hline 6 & 2 & 2,440 & .00082 \\
\hline 7 & 1 & 593 & .00169 \\
\hline 8 & 10 & 747 & .01339 \\
\hline 9 & 11 & 792 & .01389 \\
\hline 10 & 43 & 4,102 & .01048 \\
\hline 11 & 40 & 7,286 & .00549 \\
\hline 12 & 136 & 16,181 & .00840 \\
\hline $11,12,1$ & 218 & 29,028 & .00751 \\
\hline $2,3,4$ & $60 !$ & 5,799 & .01035 \\
\hline $5,6,7$ & 5 & 3,529 & .00142 \\
\hline $8,9,10$ & 64 & 5,641 & .01135 \\
\hline
\end{tabular}


TABLE 13: NCSS Estimated Probability of Fatality by Delta $V$.

\begin{tabular}{|c|c|c|c|}
\hline Delta V & Fatalities & $\begin{array}{l}\text { All } \\
\text { Occupants } \\
\end{array}$ & $\begin{array}{l}\text { Estimated } \\
\text { Probability } \\
\text { of Fatality }\end{array}$ \\
\hline $00-06$ & 1 & 5,939 & .00017 \\
\hline $07-12$ & 8 & 12,484 & .00064 \\
\hline $13-18$ & 17 & 7,192 & .00236 \\
\hline $19-24$ & 28 & 2,896 & .00967 \\
\hline $25-30$ & 42 & 1,249 & .03363 \\
\hline $31-36$ & 39 & 628 & .06210 \\
\hline $37-42$ & 22 & 328 & .06707 \\
\hline $43-48$ & 14 & 68 & .20588 \\
\hline Over 48 & 55 & 220 & .25000 \\
\hline known & 226 & 31,004 & .00729 \\
\hline Unknown & 216 & 27,065 & .00798 \\
\hline $00-12$ & 9 & 18,423 & .00049 \\
\hline Over 12 & 217 & 12,581 & .01725 \\
\hline \multicolumn{4}{|c|}{ Percentages of known delta $V$ : } \\
\hline & $\begin{array}{l}\text { ies: } \\
\text { upants: }\end{array}$ & & \\
\hline
\end{tabular}




\section{Fatality by 0ccupant Factors}

Table 14 presents seating information for fatalities, all occupants, and the fatality rate. The total shown for a row or column may be larger than the sum of the elements because of unknown data, or categories not shown. For example, the number of people killed while Tying across the third seat would be included in the total for the third seat location, but not in any of the associated seat areas shown.

Sitting in the second seat location and/or in the middle seat area is associated with a lower fatality rate. The driver's seat has the highest estimated probability of fatality, and 64 percent of the total occupants were driving when the accident occurred. The third seat location does not have enough data for a meaningful fatality rate.

Fatality data by age and sex is summarized in Table 15. The unknown rates for these variables are very low: both age and sex are known for approximately 99 percent of the file. For those few cases where, for example, the age of a male is not known, the occupant is included only in the column total for males. Therefore, totals are sometimes slightly higher than the sum of the categories of the variable as shown.

While females account for 41 percent of the total occupants, only 31 percent of the fatalities are female. This is reflected in the fatality rates by sex. Males have almost 1.6 times the fatality rate of females. 
The totals across sex of the four age categories shows a steady increase in the fatality rate with the increase in age. Within each age category, females have the lower fatality rate. A multinlicative model can be used to quantify the separate effects of age and sex on the fatality rate, and perhaps provide insight into the probability of fatality as estimated by the data. This is done in a later section.

The fact that seating position, age, and sex appear related to the fatality rate helps to explain the wide range of injuries suffered by different people in similar accident situations, and by the various occupants of a single accident. However, it does not immediately suggest means of reducing the risk of fatality or injury.

Restraint use is one variable which is almost entirely the result of conscious choice on the part of the individual. Most cars are equipped with a restraint system and most people are physically able to wear them. However, of all occupants on the NCSS file whose restraint use was known, only 8 percent were using any kind of restraint. For fatalities, only 5 percent were restrained. The data is shown in Table 16.

The estimated probability of fatality for increasingly restrained categories (no restraint, lap only, lap and torso) decreases steadily (from .005 to .004 to .002 ). An estimate of the percent reduction in the rate resulting from restraint effectiveness can be computed as follows for the fatality rates of the restraint system:

$$
\text { Effectiveness }=\text { percent reduction in fatality rate }
$$




$$
=\frac{\begin{array}{l}
\text { Rate with } \\
\text { (no restraint) }-\left(\begin{array}{l}
\text { Rate with } \\
\text { restraint }
\end{array}\right)
\end{array}}{\text { (Rate with no restraint) }} \times 100
$$

Using this formula, unadjusted for any other differences that may exist between the various occupant groups, results in the following estimates of belt effectiveness:

$$
\text { lap only: } \quad \frac{.00545-.00421}{.00545}=23 \%
$$

$$
\text { lap and torso: } \frac{.00545-.00236}{.00545}=57 \%
$$

These estimates are necessarily crude because of the small number of restrained occupants, but do indicate that restraints are effective in reducing the death rate.

The issue of restraint use is related to that of ejection. Table 16 shows the higher fatality rates associated with ejection types, especially total ejection. Partial ejectees have 28 times the fatality rate of nonejectees. Total ejectees have an even higher rate -45 times that of non-ejectees. Fully one-fifth of ejectees are killed in the accident. While only 1 percent of all occupants are ejected to some degree, these people represent almost 29 percent of the fatalities.

For those occupants about whom entrapment information is available, only 0.7 percent were trapped in the vehicle, but these are almost . 26 percent of all fatalities. Entrapment does not include doors which are locked by damage, but only cases where a part of the occupant's body is physically restrained by the vehicle. Trapped occupants have almost 42 times the fatality rate of non-trapped occupants. 
Ejection and entrapment are, at least in part, measures of the severity of the accident and the amount of energy absorbed in the crash. Also, the high fatality rate for ejectees is consistent with that for rollovers, because ejection is often a result of a rollover. Table 17 separates ejection status by rollover and non-rollover accidents.

Note the difference for the two types of accidents. In both cases, ejections coincide with a higher rate of fatality, but the relative risk of partial ejection vs total ejection is reversed. For non-rollovers, the fatality rate of partial ejectees is almost 18 times that of non-ejectees; for total ejectees, the rate is almost 44 times that of non-ejectees. However, for rollovers it is partial ejections which have the highest fatality rate. Total ejectees have over 20 times the rate for non-ejectees, but for partial ejectees vs nonejectees, the rate is 30 times as high. Possibly, when a vehicle is rolling, it is less dangerous to be thrown clear than to be partially ejected and risk being crushed as the vehicle continues rolling.

The table also shows that almost 13 times as many occupants are ejected in rollovers as in non-rollovers. Of 1,914 rollover occupants with known ejection status, $8,9 \%$ were ejected. For non-rollovers, $0.8 \%$ of occupants with known ejection status were ejected.

ihe figures in Table 18 are presented to indicate the extent to which occupant descriptors affect a narticular person's risk of fatality. The Abbreviated Injury Scale (AIS) is a standardized dictionary of injuries and an associated severity level. The severity 
ranges from 0 (no injury) through 6 (currently untreatable). Typical examples of the rating are included in Table 21 as illustrations. The overall AIS (OAIS) assesses the net effect of the combined injuries, and is generally equal to the highest individual injury sustained. The scale does not reflect such considerations as occupant age or general health. An amputated arm receives a rating of 4 , despite an individual's ability to recover from such an injury.

The injuries sustained ranged from one person who died as the result of minor injuries (OAIS of 1 ) through the 88 who died from injuries which are currently untreatable (OAIS of 6 ). Death is the result of the combination of the specific injury and the individual's reaction to it.

In over half of the cases, there were no injuries or injury levels recorded. These people are rated as an OAIS of 8 (injury severity unknown) because they were not examined by a physician. In areas where the coroner is not a medical doctor, no medical report is filled out. Thus, information on the nature of the injuries and the associated contact points is not available on the NCSS computer file,

Further information on injury coding is available in a handbook, The Abbreviated Injury Scale (AIS), developed as a joint effort of the American Medical Associated, The Society of Automotive Engineers, and the American Association for Automotive Medicine. (Reference 6) 
TABLE 14: NCSS Estimated Probability of Fatality by Seat Location

Fatalities

\begin{tabular}{lcccr} 
& \multicolumn{4}{c}{ Seat Area } \\
Location & Left & Middle & Right & //Total \\
Front & 292 & 10 & 91 & 394 \\
Second & 11 & 6 & 18 & 36 \\
Third & - & 1 & - & 1 \\
Total & 303 & 17 & 109 &
\end{tabular}

A11 0ccupants

Seat Area

\begin{tabular}{lrrrr} 
Location & Left & Middle & Right & //Total \\
Front & 36,990 & 2,066 & 12,059 & 51,236 \\
Second & 2,214 & 1,148 & 2,532 & 6,210 \\
Third & 2 & 2 & 1 & 57 \\
\hline Total & 39,207 & 3,216 & 14,593 &
\end{tabular}

Ratio (Fatalities/All Occupants)

\section{Seat Area}

$\begin{array}{lllll}\text { L.ocation } & \text { Left } & \text { Middle } & \text { Right } & \text { //Total } \\ \text { Front } & .00789 & .00484 & .00755 & .00769 \\ \text { Second } & .00497 & .00523 & .00711 & .00580 \\ \text { Total } & .00773 & .00529 & .00747 & \end{array}$


TABLE 15: NCSS Estimated Probability of Fatality by Age and Sex

Fatalities

\begin{tabular}{|c|c|c|c|}
\hline 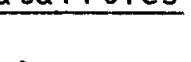 & & & \\
\hline Age & Male & Fema le & $/ /$ Total \\
\hline Under 20 & 87 & 39 & 126 \\
\hline $20-29$ & 104 & 42 & 146 \\
\hline $30-39$ & 46 & 11 & 57 \\
\hline Over 39 & 66 & 42 & 108 \\
\hline Total & 305 & 136 & \\
\hline
\end{tabular}

All Occupants

Sex

\begin{tabular}{lrrr} 
Age & Male & Female & //Tota1 \\
Under 20 & 10,349 & 7,310 & 17,734 \\
$20-29$ & 11,423 & 7,102 & 18,556 \\
$30-39$ & 3,959 & 3,121 & 7,120 \\
Over 39 & 7,285 & 6,014 & 13,323 \\
\hline Tota & 33,558 & 23,765 &
\end{tabular}

Ratio (Fatalities/All Occupants)

$\underline{\text { Sex }}$

$\begin{array}{llll}\text { Age } & \text { Male } & \text { Female } & \text { //Total } \\ \text { Under 20 } & .00841 & .00534 & .00710 \\ 20-29 & .00910 & .00591 & .00787 \\ 30-39 & .01162 & .00352 & .00801 \\ \text { Over 39 } & .00906 & .00698 & .00811 \\ \text { Total } & .00909 & .00572 & \end{array}$


TABLE 16: NCSS Estimated Probability of Fatality by Restraint Use, Ejection, and Entrapment

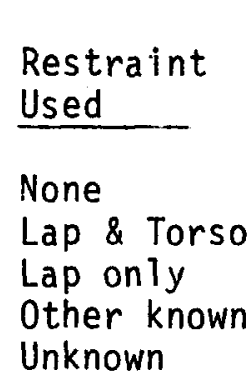

Ejection

None

Total

Partial

Unknown

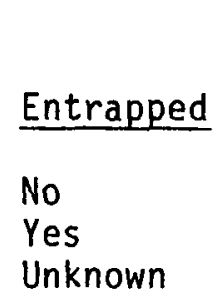

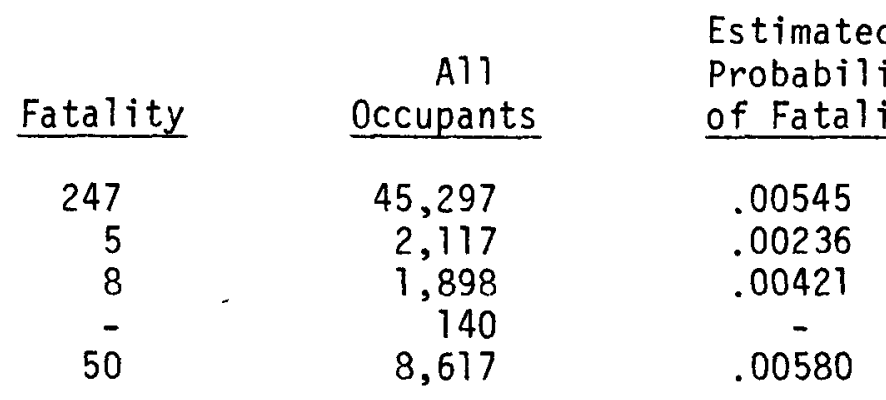

Percentages of known restraint use:

Fatalities: $\quad 79.8 \%$

All occupants: $81.0 \%$

\begin{tabular}{|c|c|c|}
\hline Fatality & $\begin{array}{c}\text { All } \\
\text { Occupants } \\
\end{array}$ & $\begin{array}{l}\text { Estimated } \\
\text { Probability } \\
\text { of Fatality }\end{array}$ \\
\hline $\begin{array}{r}273 \\
93 \\
17 \\
59\end{array}$ & $\begin{array}{r}56,911 \\
429 \\
125 \\
604\end{array}$ & $\begin{array}{l}.00480 \\
.21678 \\
.13600 \\
.09768\end{array}$ \\
\hline Fatality & $\begin{array}{c}\text { Al1 } \\
\text { Occupants } \\
\end{array}$ & $\begin{array}{l}\text { Estimated } \\
\text { Probability } \\
\text { of Fatality }\end{array}$ \\
\hline $\begin{array}{r}267 \\
79 \\
96\end{array}$ & $\begin{array}{r}56,926 \\
404 \\
739\end{array}$ & $\begin{array}{l}.00469 \\
.19554 \\
.12991\end{array}$ \\
\hline \multicolumn{3}{|c|}{ Percentages of known ejection/entrapment: } \\
\hline $\begin{array}{l}\text { Fatalities: } \\
\text { All occupants: }\end{array}$ & \multicolumn{2}{|c|}{$\begin{array}{l}86.7 \% \\
98.7 \%\end{array}$} \\
\hline
\end{tabular}


TABLE 17: NCSS Estimated Probability of Fatality by Rollover and Ejection Status

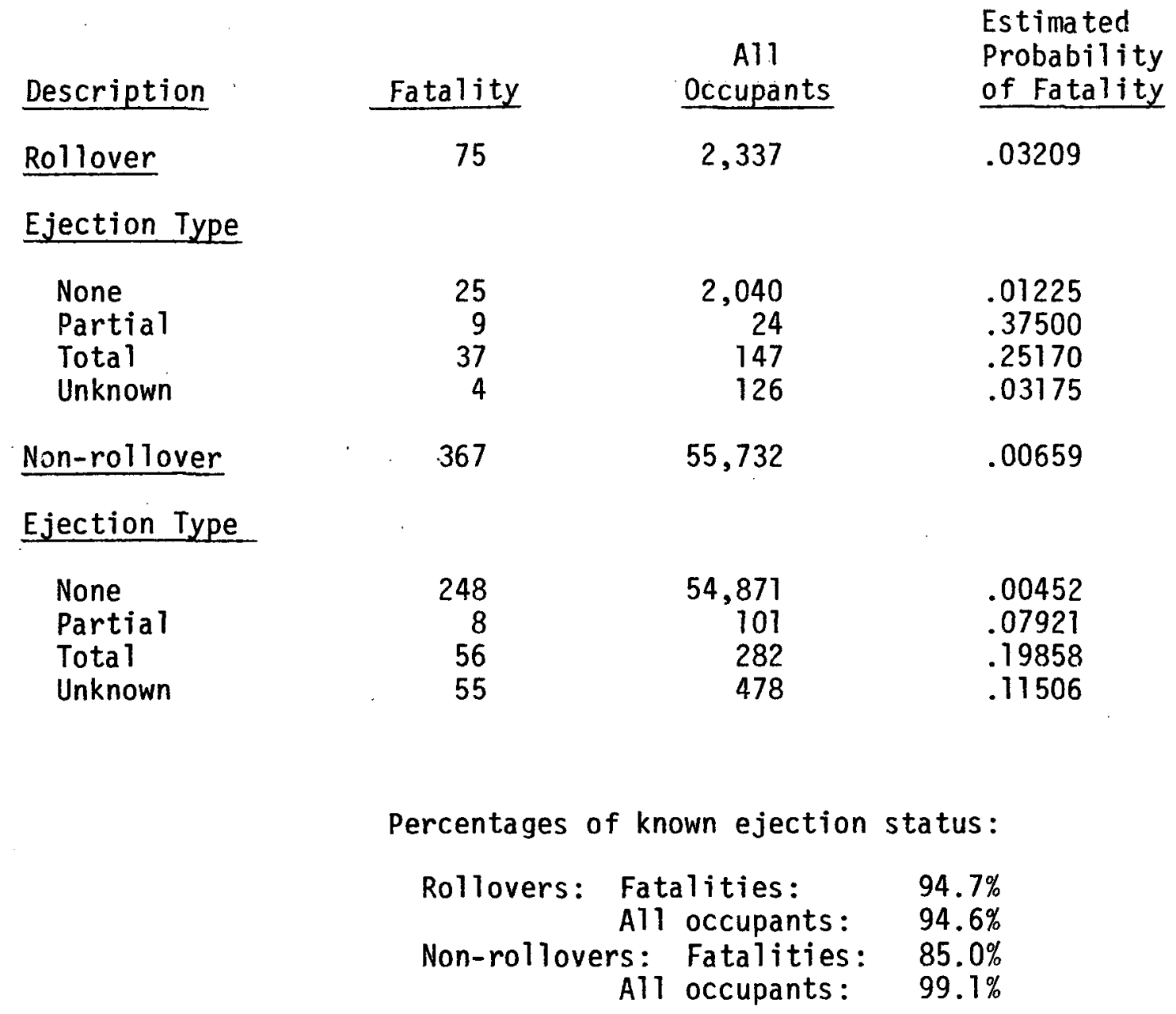


TABLE 18: NCSS Probability of Fatality by Overall AIS

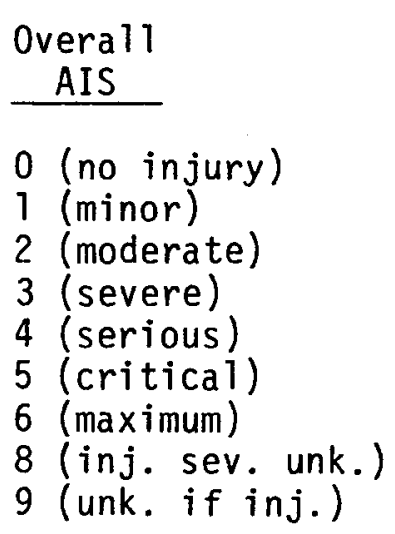

AIS Level

1
2
3
4
5
6

\begin{tabular}{ccc} 
Fatalities & $\begin{array}{c}\text { All } \\
\text { Occupants }\end{array}$ & $\begin{array}{l}\text { Estimated } \\
\text { Probability } \\
\text { of Fatality }\end{array}$ \\
\cline { 2 - 3 } & 27,622 & - \\
- & 7,999 & .00013 \\
4 & 1,631 & - \\
17 & 823 & .00486 \\
92 & 209 & .08134 \\
88 & 168 & .54762 \\
235 & 88 & 1.00000 \\
- & 9,163 & .02565 \\
Percentages of known overall AIS: \\
Fatalities: & 9,956 & - \\
All occupants : & $46.8 \%$ &
\end{tabular}

Typical Injury

arm-superficial laceration arm-deep laceration wrist-dislocation spleen-rupture kidney-rupture head-decapitation 
Fatality Rate Summary

At the accident level, several variables had different fatality rates associated with them. Single-vehicle accidents had higher rates, in particular, side collisions into fixed objects and rollovers. Of multivehicle accidents, head-on collisions had the highest proportion of fatally injured occupants. Rural accidents and those involving fire also had higher than average fatality rates.

Vehicle size appears to be an advantage in accidents, but quantifying this effect is complicated by the towing criterion, and the differences in the vehicle reaction to a crash. In a two-car, side impact with both vehicles requiring towing, occupants of the striking car appear to have the advantage. Direct impacts, as determined by the direction of force, and high impact speeds, as measured by delta $V$, result in higher than average fatality rates.

Several occupant characteristics also appear to increase the risk of fatality. In particular, front or outside (left or right) seating, older age categories, and males are associated with higher fatality rates. Restraint use, non-ejection, and non-entrapment are associated with lower fatality rates. Fatalities are the result of a wide range of injuries, as indicated by the Overall AIS. 


\section{PART 4: CONTINGENCY TABLE ANALYSES}

Objective

It is sometimes possible to sort out the effects of two interacting variables on the fatality rate. This was suggested by four pairs of variables given in the previous section: seat area by location, age by sex, sex by seating area, and rollover by ejection. In each case, both factors were affecting the fatality rate, but it was difficult to quantify the separate effect of each. A simplified model of the NCSS data produced by the APL version of the CONTAB alogrithm produces a good fit of fatality by each of these pairs of factors.

CONTAB is a tool of contingency table analysis. It is an iterative program which fits an idealized model of the data under such assumptions of independence as are specified by the analyst, and then measures the closeness of the fit. For each of the three cases in the following section, the assumption was made that each of the two factors in the model was independent of the other in its effect on the fatality rate. The model associates changes in the levels of the variable factor with changes in the risk of fatality. One possible interpretation of the model is that these changes in the factors cause changes in risk. However, this hypothesis cannot be accepted without careful investigation of other evidence and knowledge of the physical situation in each case.

The next three sections describe the results of fitting models to the NCSS data and give additional explanation of the modeling process. 
The Information in Contingency Tables by D. Gokhole and S. Keillback is a useful reference for the concepts involved in this process, as well as for the practical aspects of using a CONTAB computer program. (Reference 7) 
Model of Seat Area and Location

In an attempt to separate the effect of the seat area from that of the location, the CONTAB program was used to fit a model to the data. A model which fits the data will produce estimates of the effects of each variable. In this case, it means that an estimate of the increased risk associated with the front seat can be made independently of the effect of left vs middle vs right seat.

Table 19 shows the result of the model fitting under the assumption that the two variables act independently to determine the fatality rate. The statistics at the top of the page measure the goodness-of-fit of the mode 1 to the data. The Information Statistic (I.S.) and the Degrees of Freedom (D.F.) determine the Probability (P) of two independent variables differing as much as do these data from the model produced. This model produces a fit close enough that half of all independent relationships would differ this much from a similar model. No adjustments in the probability have been made for the effect of the weighting factor on the sample.

The actual data and the estimates from the model (in parenthesis) are shown for fatalities and non-fatalities. Since the model fits sufficiently well, it is useful to interpret the model. The odds ratio of the 'model is computed by dividing fatalities by non-fatalities for each seating category. For example, the fatality odds for a driver are $(288.9) /(36,701.1)=.0079$. The model estimates the relationships between the odds ratios. For each seat area, the value for the front 
seat is 1.2 times that for the second seat. For each location (front or second), the value is just sijghtly higher for the left seat than for the right; and for each, it is 1.5 times that for the middle seat area. Thus the model shows an increased odds of fatality associated with the window seats and front seat, and a quantification of each. 
TABLE 19: NCSS Data and CONTAB Fitted Model of Fatality by Seat Location; I.S. $=1.37 ;$ D.F. $=2 ; P=0.50$

Fatalities

\section{Seat Area}

$\begin{array}{lccc}\text { Location } & \text { Left } & \text { Middle } & \text { Right } \\ \text { Front } & 292(288.9) & 10(11.0) & 91(93.1) \\ \text { Second } & 11(14.1) & 6(5.0) & 18(15.9)\end{array}$

Non-fatalities

\section{Seat Area}

$\begin{array}{lccc}\text { Location } & \text { Left } & \text { Middle } & \text { Right } \\ \text { Front } & 36,698(36,701.1) & 2,056(2,055.0) & 11.968(11,965.9) \\ \text { Second } & 2,203(2,199.9) & 1,146(1,143.0) & 2,514(2,516.1)\end{array}$

Ratio from Model: Fatalities/Non-fatalities

\begin{tabular}{lccr} 
& & \multicolumn{2}{c}{ Seat Area } \\
Location & Left & Middle & Right \\
Front & .0079 & .0054 & .0078 \\
Second & .0064 & .0044 & .0063 \\
Inferences from Model & & \\
\hline & & & \\
& & &
\end{tabular}


Model of Age and Sex

Table 20 shows the data from the NCSS file and the results of the CONTAB model ( in parentheses) under the assumption that age and sex are independent of each other in their effect on the fatality rate. The model fits well enough to be a useful interpretation of the data: approximately 65 percent of all independent relationships would have at least this large a descrepancy between the raw data and the idealized model, just by chance. This is a measure of the confidence in the model as an explanation of the data.

The model implies that the odds of fatality for males is 1.6 times that of females, and that the odds for people under 30 is 1.1 times that for the older group. A female under 30 has the lowest odds ratio, .0055 ; and a male of 30 years or more has the highest odds ratio, .0099 . This reflects the effects of the higher risk implied by both his sex and his age. 
TABLE 20: NCSS Data and CONTAB Fitted Model of Fatality by Age and Sex I.S. $=0.203 ;$ D.F. $=1 ; P=0.65$

Fatalities

$\underline{\operatorname{Sex}}$

Age

Male

Female

Under 30

$191(193.1)$

$81(78.9)$

30 and over

$112(109.9)$

$53(55.1)$

Non-fatalities

$\underline{\text { Sex }}$

Age

Male

Female

Under 30

$21,581(21,578.9)$

$14,331(14,333.1)$

30 and over

$11,132(11,134.1)$

$9,082(9079.9)$

Ratio from Model: Fatalities/Non-fatalities

$\underline{\text { Sex }}$

$\begin{array}{lcc}\text { Age } & \text { Male } & \text { Female } \\ \text { Under } 30 & .0089 & .0055 \\ 30 \text { and over } & .0099 & .0061\end{array}$

Inferences from Model

The odds of fatality are:

1.1 times as high for the older group as for the younger

1.6 times as high for males as for females 


\section{Model of Sex and Seating Location}

A confounding aspect of the estimation of the odds of fatality, by either seating location or by sex, is that males are much more likely to be driving during an accident than are females. While 72 percent of the males on the NCSS file were driving when the accident occurred, only 53 percent of the females involved were drivers in the accident.

The model presented in Table 21 attempts to sort out these two effects (sex and whether or not the person was a driver) using tools of contingency table analysis. The better fit of the data resulted when sex was used as a predictor of fatality, but seating location was not. Inclusion of the seating location as a factor did not significantly improve the accuracy of the prediction, and this model was discarded.

Therefore, the estimates from the model shown in the table are that males have 1.6 times the odds ratio of fatality that females have, and that this ratio does not depend on whether or not the person was driving at the time of the accident. It appears that the higher percentages of males who were drivers is not a cause of their higher fatality rate. 
TABLE 21: NCSS Data and CONTAB Fitted Model of Fatality by Sex and Seating Location; I.S. $=3.147 ;$ D.F. $=2 ; P=0.21$

Fatalities

Seating Location

$\underline{\text { Sex }}$

$\begin{array}{lr}\text { Driver } & \text { Non-Driver } \\ 228(219.6) & 77(85.4) \\ 64(72.1) & 72(63.9)\end{array}$

Non-Fatalities

Seating Location

$\underline{\text { Sex }}$

$\begin{array}{cc}\text { Driver } & \text { Non-Driver } \\ 23,933(23,941.4) & 9,320(9,311.6) \\ 12,542(12,533.9) & 11,087(11,095.1)\end{array}$

Ratio from Model: Fatalities/Non-Fatalities

Seating Location

Sex

Male

Female
Driver

.0092

.0058
Non-Driver .0092 .0058 


\section{Model of Rollover and Ejection}

The CONTAB algorithm was used on the ejection/rollover data in an attempt to separate out the effects of the two variables. Table 22 gives the NCSS data and the value produced by the model (in parenthesis) using ejection as a yes/no variable. The model fits well enough that 20 percent of all independent relationships would have a larger descrepancy between the data and the model of independence, as measured by the information statistic and the degrees of freedom.

The odds of fatality computed from the values of the model quantify the effects of rollovers and ejections. Ejection increases the odds ratio by a factor of 40 ; rollover occupants have 2.3 times the odds ratio of non-rollover occupants. Since the model assumes independence between ejection and rollover effects, an ejectee in a rollover has an odds ratio equal to the odds ratio of a non-ejected, non-rollover. occupant times the product of the increments of the two variable effects. That is,

$$
.4147=.0046 \times 39.9 \times 2.3
$$

This model does not take into account the difference between total and partial ejections. These effects are too interrelated with the rollover variable, as shown in Table 17 , to be able to be able to fit an independence model. 
TABLE 22 : NCSS Data and CONTAB Fitted Model of Fatality by Rollover and Ejection I.S. $=1.669 ;$ D.F. $=1 ; P=0.20$

Fatalities

\section{Rollover}

Ejection

Yes

No

Yes

$46(50,1)$

$64(59.9)$

No

$25(20.9)$

$248(252.1)$

Non-fatalities

Rollover

\begin{tabular}{lccc} 
Ejection & \multicolumn{1}{c}{ Yes } & No \\
Yes & $125(120.8)$ & $319(323.2)$ \\
No & $2,015(2,019.2)$ & $54,623(54,618.8)$
\end{tabular}

Ratio from Model: Fatalities/Non-fatalities

\section{Rollover}

Ejection
Yes
No
Inferences from Model
The odds of fatality are:
39.9 times as high for ejectees as for non-ejectees
2.3 times as high for rollover as for non-rollover
occupants


Summary of Models

These models are useful in quantifying the risk of fatality and suggest the relative sizes of these risks:

Model: seat area and location

front seat vs rear seat $\quad 1.2$

window seàt vs middle seat $\quad 1.5$

Mode 1: age and sex

old vs young 1.1

$\begin{array}{ll}\text { male vs female } & 1.6\end{array}$

Model: sex and seating location

male vs female $\quad 1.6$

driver vs other passenger $\quad 1.0$

Model: rollover and ejection

rollover vs non-rollover $\quad 2.3$

ejection vs non-ejection $\quad 39.9$

Certain characteristics on the NCSS file are more often associated with fatality than are others, and it is possible to estimate the incremental risk using these models. This is not the same as identifying the cause of the increased risk. The models do not take into account the different driving habits of various age groups, or their tendencies toward certain models, sizes, or ages of cars. 
Rollovers and ejection are associated with a much higher fatality rate. Preventing rollover and ejection will have the effect of lowering that rate if people are killed by the vehicle rolling onto them or by severe impacts as they strike the ground. However, to a certain extent rollover and ejection are also indications that the vehicle was moving very fast at the time that the driver lost control, or was struck very hard by another vehicle. These accidents will still have a high risk of fatality even if rollover and ejection are reduced.

In summary, while models are useful in quantifying relationships and separating out complicating factors, they are limited in actual interpretations of results. They are best used as indications of possible productive areas of future study. 
PART 5: CONCLUSION

The objective of this study has been to investigate the fatalities on the National Crash Severity Study. To do this, it has seemed desirable to, first of al1, put NCSS in the context of the national experience of traffic deaths by comparing these fatalities to those on the Fatal Accident Reporting System. The census information available on FARS differs from the NCSS on some key variables: number of vehicles involved, rollover, age of occupant, and ejection status of occupant. Further analysis of the NCSS file will determine which of these differences are the result of the choice of sampling areas. Number of vehicles involved is an important crash descriptor, and analysis usually considers single and multi-vehicle accidents separately. Similarly occupant age is an important injury factor, and so is usually controlled for in analysis of injury severity.

On the other hand, it appears likely that the differences between the files for rollover and ejection are the results of different, but equally legitimate, coding practices. This means that the definition and decision rules for these variables are very important to a determination of their frequency of occurrence in any population.

The second aspect of the study involved estimating relative probabilities of fatality for the NCSS areas. Important factors associated with higher fatality rates were identified and quantified using fatality rates (as found in the file) and modeling techniques (ror the separation of 
correlated pairs of factors). For example, higher fatality rates were computed for accidents involving entrapment, ejection, large changes in velocity during impact, and fire in this accident. Further analysis is needed to determine which of these factors are causes of fatality and which are merely indications of the severity of the collision. 


\section{PART 6: REFERENCES}

1. Kahane, C., Smith, R., and Tharp, K., "The National Crash Severity Study" Report on the Sixth International Technical Conference on Experimental Safety Vehicles. Pub. No. DOT-HS-802-50. NHTSA Washington, D.C. 1976.

2. Hedlund, J. "A.Working Guide to the National Crash Severity Study" Unpublished report, NHTSA April, 1978.

3. 1977 FARS Annual Report. NHTSA Pub1. No. DOT-HS-8-01954 Washington, D.C. November, 1978.

4. Partyka, S. "Injury Predictors by Area of Damage to the Vehicle." Unpublished report. NHTSA JuTy, 1978.

5. Partyka, S. "Rollovers and Injury on the NCSS File." Unpublished report, NHTSA October, 1978.

6. The Abbreviated Injury Scale (AIS). American Association for Automotive Medicine. Morton Grove, I1linois, 1976.

7. Gokhale, D. and Kullback, S. The Information in Contingency Tables. Marcel Dakker, Inc. New York, 1978 
U.S. DEPARTMENT OF TRANSPORTATION

NATIONAL HIGHWAY TRAFFIC SAFETY ADMINISTRATION

Washington, D.C. 20590

Official Business

PENALTY FOB PRIVATE USE, $\$ \mathbf{3 0 0}$
POSTAGE AND fRES PAID

NATIONAL HIOHWAT TRAFPIC

BABETX ADMINISTRATION

DOT 517

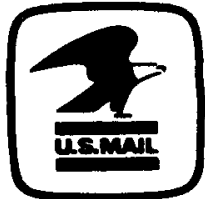

